\title{
Plantas medicinais em feiras e mercados públicos do Distrito Florestal Sustentável da BR-163, estado do Pará, Brasil ${ }^{1}$
}

\author{
Pedro Glécio Costa Lima ${ }^{2,3}$, Márlia Coelho-Ferreira² e Regina Oliveira²
}

Recebido em 17/01/2011. Aceito em 9/05/2011

\begin{abstract}
RESUMO
(Plantas medicinais em feiras e mercados públicos do Distrito Florestal Sustentável da BR-163, estado do Pará, Brasil). As plantas medicinais constituem um grupo de produtos florestais não-madeireiros apontado como de grande potencial no Distrito Florestal Sustentável da BR-163. Visando compreender a cadeia produtiva de plantas medicinais oriundas do extrativismo, comercializadas em entrepostos, feiras e mercados públicos de municípios desta área, foram realizadas entrevistas semi-estruturadas com 20 vendedores de plantas medicinais. Foi estimada a riqueza de espécies a partir do estimador Bootstrap e analisada a similaridade entre os municípios estudados, através do Índice de Sørensen. Identificaram-se 46 etnoespécies de plantas medicinais, pertencentes a 42 gêneros e 21 famílias, sendo Fabaceae, Anacardiaceae e Bignoniaceae as famílias mais representativas. A riqueza esperada foi de 50 etnoespécies, sendo que coletas adicionais acrescentariam pelo menos quatro itens à lista geral de riqueza. Com relação à similaridade, Santarém, Itaituba e Altamira compartilham um maior número de espécies, sendo que Santarém mostra-se como centro diversificado de produtos medicinais, com maior número de ocorrências exclusivas (14). As feiras e mercados públicos, por serem um elo importante desse sistema de distribuição, devem ser incluídos nas ações governamentais sobre políticas públicas para a saúde.
\end{abstract}

Palavras-chave: Distrito Florestal, Extrativismo, Produtos Florestais Não-Madeireiros, Amazônia

\begin{abstract}
(Medicinal plants at fairs and public markets of the Sustainable Forest District of BR-163, Pará state, Brazil). Medicinal plants are non-timber forest products with great potential in the Sustainable Forest District of BR-163. In order to understand the productive chain from extractive medicinal plants marketed at emporiums, fairs and public markets of districts of this area, semi-structured interviews with 20 vendors of medicinal plants were carried out. Species richness was estimated by Bootstrap and similarity among the districts studied was analyzed by Sørensen's Index. 46 medicinal plants belonging to 42 genera and 21 botanical families were identified. Fabaceae, Anacardiaceae and Bignoniaceae were the most representative botanical families. The expected richness for the sample was 50 species and additional collecting would increase by at least four items the general list of richness. Santarém, Itaituba and Altamira share a larger number of species and the first is shown to be a diversified center of medicinal products, presenting the largest number of exclusive occurrences (14). The fairs and public markets are an important link of this distribution system, and should be included in government actions concerning public policies for health
\end{abstract}

Key words: Forest District, Extrativism, Non-Timber Forest Products, Amazonian

\section{Introdução}

O governo brasileiro vem experimentando uma forma recente de ordenamento territorial para contenção do desmatamento e planejamento de uso da terra, por meio da criação de distritos florestais, os quais vêm a ser áreas especiais para a implementação da Lei de Gestão de Florestas Públicas ( $n^{\circ}$. 11.284/2006), cujo objetivo é regulamentar o uso e conservação de terras de dominialidade pública (Brasil 2006; Schittini et al. 2008). O primeiro distrito florestal cria- do corresponde à região do estado do Pará sob de influência da BR-163, mais conhecida como rodovia Santarém-Cuiabá (Brasil 2006).

Neste contexto, chama-se a atenção para as leis e planos de gestão florestal, os quais não podem abrir mão de buscar reconhecer os diferentes tipos de produtos florestais e suas utilizações tanto para a subsistência como para a comercialização. Além do cuidado em identificar a escala do comércio frente aos mercados regional e global, é importante a construção de uma matriz política mais ampla

\footnotetext{
Parte da dissertação de Mestrado do primeiro Autor

2 Museu Paraense Emílio Goeldi, Campus de Pesquisa, Belém, Pará, Brasil

3 Autor para correspondência: gleciolima@gmail.com
} 
e mais coerente com as especificidades de cada produto florestal, evitando-se cair no erro de investir em regulamentações apenas nos casos em que há riscos evidentes de sobre-exploração (Laird et al. 2009).

O plano de ação do Distrito Florestal Sustentável da BR-163 (DFS/BR-163), publicado em junho de 2006, dá ênfase à cadeia produtiva madeireira, no entanto, faz referência à necessidade de avaliar a inserção da cadeia produtiva de cosméticos e biotecnologia na região, através da industrialização de óleos, resinas, folhas, essências, raízes e outros produtos florestais não-madeireiros (PFNM) (Brasil 2006). Neste contexto, as plantas medicinais constituem um grupo específico destes produtos, apontados como itens de grande potencial no distrito florestal. Mesmo assim, ainda não está claro como essa alternativa econômica irá proporcionar melhorias para os atores locais, sendo necessários maiores esclarecimentos a respeito da situação atual da cadeia produtiva das plantas medicinais para a elaboração de políticas públicas adequadas. Assim, identificar quais e quantas plantas medicinais estão inseridas no mercado local e regional vem a ser um passo importante para futuras ações.

Os estudos em mercados públicos locais vêm a ser uma estratégia importante para o reconhecimento sobre os produtos medicinais de origem florestal utilizados em uma região e podem ser levados em consideração para futuras investigações sobre a conservação das espécies exploradas (Martin 1995; Veeman 2002; Botha et al. 2004; Albuquerque et al. 2007; Monteiro et al. 2010; Mati \& Boer 2011). A Botânica Econômica e a Etnobotânica oferecem ferramentas interessantes que podem ajudar na compreensão de aspectos, como a riqueza das plantas medicinais importantes para a população local e que são comercializadas nos centros urbanos distribuídos na região do DFS/ BR-163. Ambas as disciplinas contribuem, com diferentes enfoques, em investigações desta natureza: a primeira, preocupando-se com o registro das espécies vegetais que adquiriram importância em mercados regionais e globais (Martin 1995); e a segunda, focada na compreensão contextualizada da inter-relação entre seres humanos e plantas, moldada pela história através de meios físicos e sociais (Alcorn 1995).

Esta pesquisa visa compreender a cadeia produtiva de plantas medicinais oriundas do extrativismo, comercializadas em entrepostos, feiras e mercados públicos em municípios que integram o DFS/BR-163. As questões que conduziram as discussões neste trabalho foram: quais são as plantas medicinais de origem extrativa comercializadas nos mercados e feiras destes municípios? Existe variação na riqueza de espécies entre esses mercados? Quais as partes vegetativas mais comercializadas? Como se dá o processo de comercialização desses produtos e quais os atores envolvidos nesse processo? Qual a importância das feiras, mercados e vendedores de plantas medicinais para o acesso a esses produtos na região?

\section{Material e métodos}

\section{Área de estudo}

O Distrito Florestal Sustentável (DFS) da BR-163 está localizado na região oeste do estado do Pará, correspondendo ao território que se estende de Santarém até Castelo dos Sonhos (Município de Altamira), no eixo da BR-163 (Cuiabá - Santarém), e de Jacareacanga a Trairão no eixo da BR-230 (Transamazônica) (Brasil 2006) (Fig. 1).

Esta área abrange mais de 19 milhões de hectares e compreende os municípios de Altamira, Aveiro, Belterra, Itaituba, Jacareacanga, Novo Progresso, Placas, Rurópolis, Santarém e Trairão. A região conta com mais de $90 \%$ de área ocupada por florestas com predominância de terras públicas (Brasil 2006). Nesta pesquisa foram realizados levantamentos em seis dos dez municípios: Altamira, Aveiro, Itaituba, Jacareacanga, Rurópolis e Santarém, sendo que em Altamira, a sede municipal encontra-se na área de influência da rodovia BR-163, como consta no Zoneamento Ecológico-Econômico realizado para a região (Venturieri 2008). O Município de Novo Progresso não foi incluído na amostra em virtude das dificuldades de acesso à região. Já em Belterra, Placas e Trairão não foi identificada a comercialização de plantas medicinais nas feiras e mercados.

A região abrangida pelos municípios aqui considerados caracteriza-se por apresentar um clima quente e úmido. A precipitação anual varia entre $1.800 \mathrm{~mm}$ e $2.800 \mathrm{~mm}$, com uma divisão na distribuição das chuvas, sendo um período com chuvas abundantes (janeiro a julho) e outro com baixa precipitação (agosto a dezembro). A umidade relativa do ar varia de 80 a $90 \%$ (Venturieri 2008).

A vegetação local é diversificada. Apesar da acelerada exploração dos recursos florestais, aproximadamente 70\% da cobertura vegetal original está conservada, principalmente em áreas distantes das rodovias federais, onde as frentes de ocupação se instalaram. Com o predomínio de florestas ombrófilas de terra firme, na região também ocorrem florestas sub-montanhosas, florestas semidecíduas e manchas savânicas (Almeida et al. 2008).

Entre as atividades econômicas desenvolvidas, se destaca a agricultura, cujos principais produtos são a mandioca, o arroz, o milho e, mais recentemente, a soja. A pecuária bovina também tem aumentado, principalmente para a produção de gado de corte. Já a atividade florestal madeireira tem uma importância econômica significativa para a região. Mais de $80 \%$ da madeira explorada tem como destino o mercado do Centro-Sul do País, maior consumidor mundial de produtos tropicais. A mineração declinou a partir dos anos noventa e a exploração de produtos florestais não-madeireiros é baixa na economia regional (Venturieri 2008). 


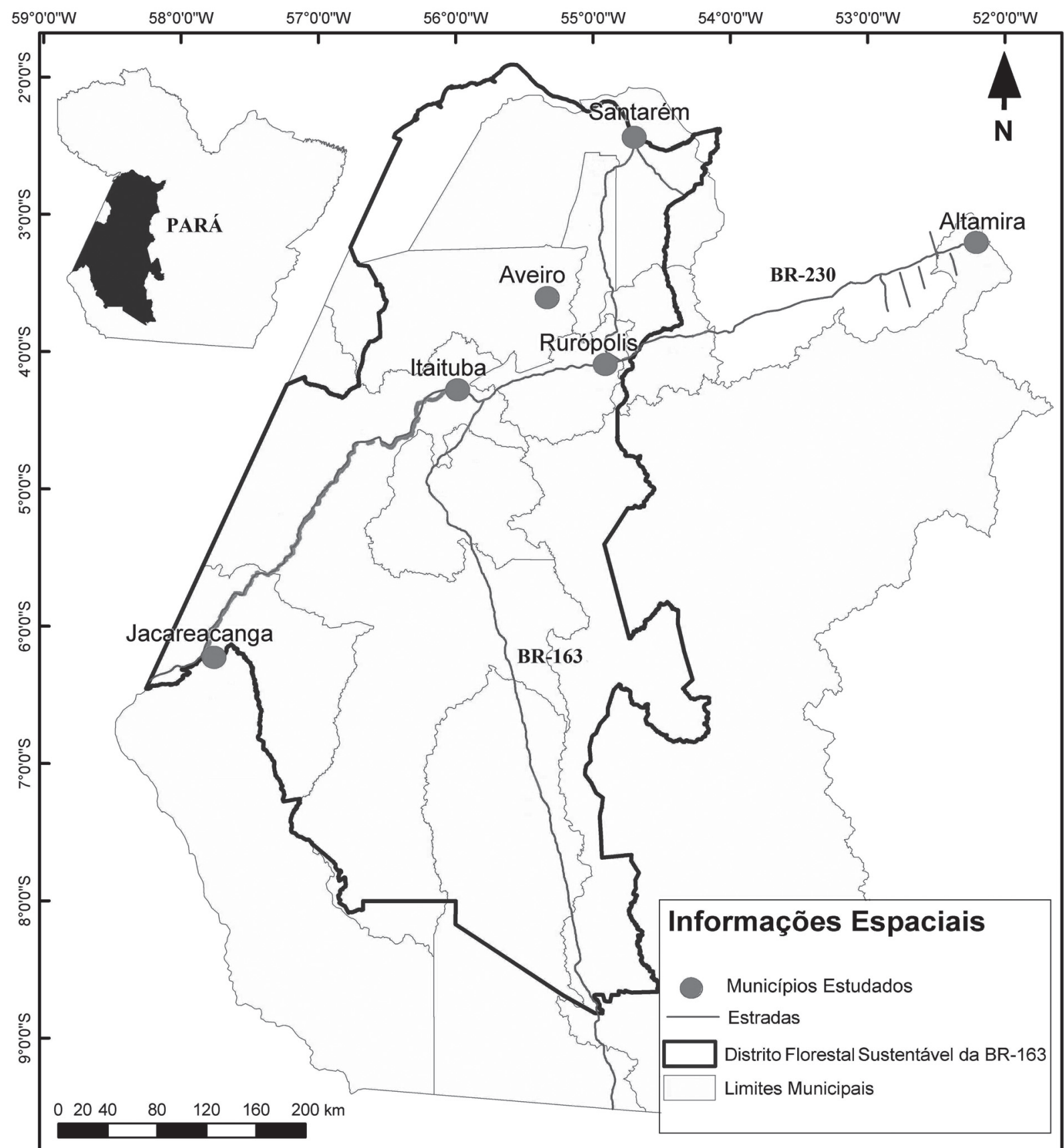

Figura 1. Mapa de localização dos municípios estudados, DFS/BR-163, Pará, Brasil. Fonte: UAS/MPEG.

\section{Coleta e análise dos dados}

Em cada município, foram primeiramente visitados os locais de comercialização de plantas medicinais, representados por mercados municipais, feiras, entrepostos. Para este estudo o termo feira refere-se à nomeação local atribuída a espaços específicos destinados à comercialização de produtos agroextrativistas e da pesca. As feiras podem apresentar estrutura física permanente ou temporária, podendo funcionar diariamente ou uma vez por semana. Os mercados municipais, por sua vez, apresentam estruturas permanentes, geralmente padronizadas e com funcionamento diário. Já os entrepostos são definidos neste estudo como pontos de comercialização que se encontram dispersos na cidade, como por exemplo, pontos de vendas em residências e vendedores de rua. No total foram entrevistados 20 vendedores durante cinco viagens de campo, as quais foram realizadas entre novembro de 2008 e setembro de 2009.

Neste trabalho deu-se enfoque às plantas medicinais oriundas do extrativismo no DFS/BR-163, sendo assim, 
consideraram-se apenas os produtos obtidos de espécies não cultivadas, conforme a indicação dos informantes. Para a obtenção de dados sobre as plantas medicinais, a origem dos produtos, época em que cada produto chegava ao mercado, parte vegetativa utilizada, as formas de armazenamento e conservação, bem como sobre a comercialização, foram realizadas entrevistas semi-estruturadas, conforme Martin (1995) e Albuquerque et al. (2008). Os dados coletados incluíram idade, local de origem, grau de escolaridade, principal fonte de renda, tempo em que comercializam produtos e porque comercializam estes produtos. Adicionalmente foram realizados registros fotográficos e anotações em diários de campo.

A identificação das espécies foi fundamentada na literatura científica disponível, fazendo-se a correspondência dos nomes vernaculares citados e os respectivos nomes científicos encontrados. Para algumas cascas recorreu-se à consulta a especialistas, à observação das características organolépticas e macroscópicas, bem como à comparação com material da coleção da Xiloteca do Museu Paraense Emílio Goeldi. Não foi possível coletar material botânico nas condições admitidas para a herborização, uma vez que os produtos comercializados são procedentes de localidades, cujo acesso foi impossível. Albuquerque et al. (2007) documentaram a recorrência da dificuldade exposta e explicam que devido se tratar de partes de vegetais, a coleta de amostras de material para a identificação fica prejudicada, havendo que se recorrer às informações científicas disponíveis ou realizar tentativas de identificação através de procedimentos farmacobotânicos.

Este procedimento já havia sido considerado e efetuado por Williams et al. (2000) e Williams et al. (2005), os quais utilizaram o termo "etnoespécie", que, conforme Hanazaki et al. (2000), tem em conta o nome folk ou comum dado a uma ou várias espécies cotadas durante as entrevistas. A aquisição de amostras de cascas e óleos compôs uma pequena coleção de material testemunho e mostrou-se como uma estratégia facilitadora da interlocução com os vendedores. Produtos, como látex e seivas, não foram adquiridos, em razão de sua perecibilidade. O sistema de classificação botânica adotado foi o APG III (2009).

Para se verificar a suficiência amostral, foi construída a curva de rarefação, que consiste em calcular o número esperado de espécies em cada amostra para um tamanho de amostra padrão (Peroni et al. 2008). Para a aplicação na etnobotânica, a curva de rarefação é construída a partir do número de espécies conhecidas ou utilizadas por um determinado grupo humano, considerando o número de citações de cada etnoespécie em cada entrevista que compõe uma amostra (Hanazaki et al. 2000). Segundo Peroni et al. (2008), a curva de rarefação pode ser comparada com curvas obtidas a partir de estimadores de riqueza, os quais permitem estimar o número total de espécies a partir dos dados amostrais. Para este estudo foi utilizado o estimador Bootstrap, o qual é calculado pela fórmula:

$$
S_{b o o t}=S_{o b s}+\sum_{K=1}^{S o b s}\left(1-p_{K}\right)^{m}
$$

Onde:

$S_{o b s}$ : número total de etnoespécies observado.

$p_{K}$ : proporção de amostras que contém a etnoespécie $\mathrm{K}$. $m$ : número total de amostras.

Tanto a curva de rarefação quanto a curva do estimador foram geradas por meio do programa Estimate Swin 8.20.

Também foi utilizado o índice de similaridade de Sørensen, o qual tem sido aplicado em trabalhos etnobotânicos para comparações de espécies úteis em comunidades diferentes, independentemente da amostragem da vegetação, sendo recomendado para situações em que se deseje valorizar a ocorrência simultânea de uma espécie em duas unidades comparadas (Araújo \& Ferraz 2008). Neste estudo, o índice serviu para comparar a semelhança entre os municípios estudados em termos de composição de etnoespécies. Considerou-se o total de plantas medicinais mencionadas pelo conjunto de vendedores entrevistados de cada município, sendo que não houve uma pré-definição do número de informantes por município, o que não impede a aplicação deste índice. Para esta análise foi utilizada a seguinte fórmula:

$$
S_{S}=\frac{2 a}{(2 a+b+c)}
$$

Onde:

$S_{s}$ : índice de similaridade de Sørensen.

a: número de etnoespécies comuns, mencionadas em dois municípios.

b: número de etnoespécies mencionadas apenas no município 01.

c: número de etnoespécies mencionadas apenas no município 02.

Com base na matriz de similaridade foi gerado um dendrograma de agrupamento da similaridade, utilizando-se o programa Sistat 12.0.

\section{Resultados e discussão}

\section{Caracterização dos locais de comercialização e dos vendedores}

A relação dos locais visitados e dados sobre o perfil dos vendedores entrevistados encontra-se na Tab. 1. Nos municípios estudados, a feira e o mercado são espaços socialmente instituídos para a comercialização não apenas de produtos da agricultura, mas do extrativismo de origem animal e vegetal.

As feiras, apesar de terem seu funcionamento regulado pela prefeitura e associações, apresentam estruturas normalmente rústicas, à base de madeira com cobertura de telhas de amianto ou mesmo lona. Os feirantes ficam agrupados 
Tabela 1. Perfil dos vendedores de plantas medicinais entrevistados no DFS/BR-163, Pará, Brasil. n=20.

\begin{tabular}{|c|c|c|c|c|c|c|}
\hline Município & Local de venda & Informante & Sexo & Idade & Origem & $\mathrm{N}^{\circ}$. de plantas citadas \\
\hline \multirow[t]{5}{*}{ Altamira } & Feira & 1 & $\mathrm{~F}$ & 41 & Maranhão & 13 \\
\hline & & 2 & F & 36 & Pará & 1 \\
\hline & & 3 & $\mathrm{~F}$ & 24 & Ceará & 8 \\
\hline & & 4 & M & 59 & Bahia & 24 \\
\hline & & 5 & M & 47 & Piauí & 3 \\
\hline \multirow[t]{2}{*}{ Aveiro } & Entreposto & 6 & $\mathrm{~F}$ & 69 & Pará & 6 \\
\hline & & 7 & F & 64 & Pará & 2 \\
\hline \multirow[t]{8}{*}{ Itaituba } & Feira & 8 & $\mathrm{~F}$ & 47 & Maranhão & 22 \\
\hline & & 9 & $\mathrm{~F}$ & 34 & Pará & 22 \\
\hline & & 10 & $\mathrm{~F}$ & 30 & Maranhão & 15 \\
\hline & & 11 & F & 56 & Piauí & 1 \\
\hline & & 12 & M & 67 & Maranhão & 22 \\
\hline & & 13 & M & 55 & Piauí & 6 \\
\hline & & 14 & M & 55 & Ceará & 1 \\
\hline & & 15 & M & 42 & Maranhão & 1 \\
\hline Jacareacanga & Entreposto & 16 & M & 35 & Pará & 1 \\
\hline Rurópolis & Feira & 17 & M & 57 & Maranhão & 3 \\
\hline \multirow[t]{3}{*}{ Santarém } & Feira & 18 & M & 76 & Pará & 5 \\
\hline & Entreposto & 19 & M & 64 & Pará & 21 \\
\hline & Mercado & 20 & F & 33 & Pará & 23 \\
\hline
\end{tabular}

em locais estratégicos de acordo com o tipo de produto que comercializam, podendo-se observar setores específicos, como por exemplo, setor de venda de aves e peixes, setor de frutas e verduras, setor de produtos medicinais, entre outros (Fig. 2).

O movimento nas feiras e mercados ao longo da semana pode ser variável de acordo com o período em que os produtores dirigem-se ao centro urbano para a venda de suas mercadorias, compra de mantimentos e acesso a serviços. Dentre os vários itens da produção rural trazidos para a cidade, frequentemente estão a banana, a farinha de mandioca, o arroz, o feijão, o açaí, o peixe, a castanha-do-pará e as plantas medicinais. De acordo com os informantes o fluxo de movimentação também é influenciado pelo período de recebimento de benefícios da previdência ou de programas sociais tais como o Bolsa Escola e o Bolsa Família. Foi constatada a existência de feiras temporárias em Itaituba, Santarém e Altamira, nas quais o funcionamento se dá aos domingos. Nestes casos, é comum encontrar vendedores de plantas medicinais que tem bancas fixas em outras feiras e mercados, os quais levam seus produtos e aproveitam esse comércio de fim de semana.

A existência destes espaços tem chamado a atenção sobre a persistência desta forma de organização comercial dentro dos centros urbanos. De fato, configuram-se como importantes elementos históricos da sociedade, essenciais para diversas economias regionais e que desempenham importante função cultural (Mayo 1991; Godoy \& Anjos 2002; Rozelle 2003; Albuquerque et al. 2007). Na região do DFS/

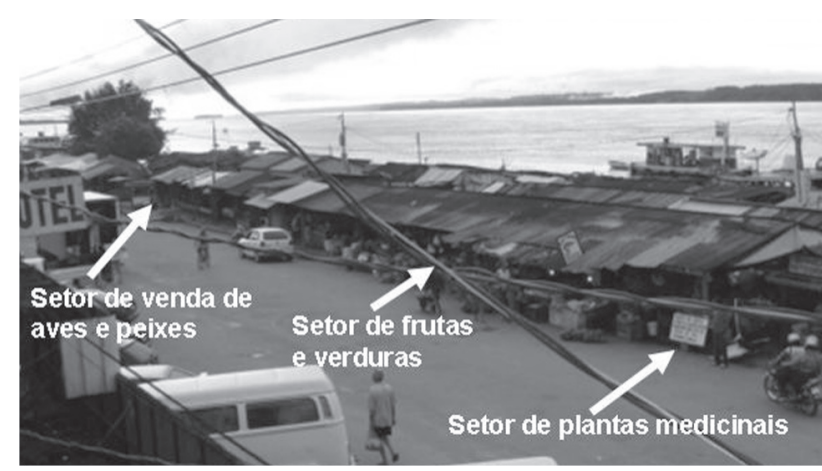

Figura 2. Feira do Produtor Rural na orla fluvial de Itaituba-PA, DFS/BR-163, Pará, Brasil.

BR-163, tais estruturas têm grande relevância para o acesso a produtos florestais e entre as funções que desempenham, ressalta-se a conexão entre o rural e o urbano, possibilitando a comercialização de produtos naturais, como as plantas medicinais coletadas na floresta.

Dentre os informantes entrevistados nestes mercados, a participação de homens e mulheres foi equilibrada (ambos com 50\%). Apenas um informante tinha menos de 30 anos, o que mostra a baixa participação de jovens nesta atividade. Observou-se a atuação coadjuvante de jovens em poucos pontos de venda, onde havia um maior envolvimento de vários integrantes de uma mesma família. Nove dos entrevistados, seis dos quais mulheres, têm idades entre 30 e 50 anos, faixa etária considerada economicamente ativa.

No que concerne à escolaridade, verificou-se um baixo grau de instrução entre estes trabalhadores, sendo que 
$50 \%(n=10)$ não concluíram o primeiro grau; $30 \%(n=6)$ não possuem escolaridade, enquanto que $15 \%(n=3)$ têm o segundo grau incompleto. Apenas $5 \%$ possuem o segundo grau completo.

Mais da metade dos informantes $(60 \% ; n=12)$ apresenta origem nordestina, principalmente dos Estados do Maranhão e Piauí. Isso reflete o histórico de migrações ocorridas na região do DFS/BR-163, conforme documentado por Castro et al. (2004) e Araújo et al. (2008).

Quanto às principais fontes de renda, 45\%(n=9) dos informantes declarou depender unicamente da comercialização de produtos medicinais na feira. Outros $(35 \% ; n=7)$, além de atuarem no comércio de plantas medicinais, obtêm benefícios sociais para a complementação da renda familiar, como o recebimento de recursos do programa Bolsa Família e de aposentadorias. Para 15\% (n=3), a produção rural é a mais importante, sendo que a venda de plantas medicinais corresponde a apenas uma parte da renda familiar. Um vendedor, além do comércio, declarou manter trabalho assalariado no setor público.

A maioria dos entrevistados $(75 \% ; n=15)$ atua exclusivamente como comerciante e depende dos produtores rurais ou de atravessadores para a obtenção das plantas medicinais. Os 25\% $(n=5)$ restantes declararam atuar como extrativistas de produtos medicinais, principalmente óleos de andiroba, piquiá e babaçu.

O tempo médio de experiência na venda de plantas medicinais é de 12 anos. O acúmulo de experiências adquiridas no trato com as plantas, de acordo com Araújo et al. (2009), capacita o vendedor para a prática da comercialização destes vegetais. A escolha em trabalhar com tais produtos medicinais pode variar de acordo com a história de vida de cada indivíduo. Para 40\% $(n=8)$, as causas estão ligadas ao envolvimento familiar, devido à influência de parentes, como pais, tios, entre outros, que já comercializavam plantas medicinais e transmitiram os conhecimentos determinantes para a escolha desta profissão. Para 30\% $(n=6)$, o trabalho com esses produtos é decorrente da sua grande procura, sendo que uma informante chegou a explicar que comprou um livro sobre plantas medicinais para ampliar seus conhecimentos. Outros vendedores $(30 \% ; n=6)$ disseram que se tratava da única fonte de renda que haviam encontrado.

Algumas vezes a comercialização de plantas medicinais funciona como uma alternativa para complementar a renda. Um informante que comercializa vinho de açaí (Euterpe oleracea Mart.) no município de Itaituba, explicou que devido à sazonalidade deste fruto, a venda de plantas medicinais garante sua renda ao longo do ano, pois os produtos são conservados por um período maior.

\section{Plantas medicinais comercializadas}

Foram catalogadas 46 etnoespécie pertencentes a 42 gêneros, distribuídas em 21 famílias botânicas (Tab. 2). O número de espécies por família variou de um a onze.
Fabaceae, Anacardiaceae e Bignoniaceae foram as mais representativas, com $24 \%$ das etnoespécies para a primeira e $9 \%$ para cada uma das seguintes. Dentre as etnoespécies catalogadas, quatro merecem destaque por terem recebido o maior número de citações $(\geq 10)$. São elas: andiroba (Carapa guianensis Aubl.), cumarú (Dipteryx odorata (Aubl.) Willd), copaíba (Copaifera spp.), verônica (Dalbergia sp.).

As plantas catalogadas estão distribuídas em três tipos de hábito: arbóreo $(87 \% ; n=40)$, arbustivo $(6,5 \% ; n=3)$ e lianescente $(6,5 \% ; n=3)$. Observa-se que o arbóreo foi predominante, o que demonstra a relevância deste componente no ecossistema florestal para o extrativismo de plantas medicinais nesta região. De fato, Albuquerque (2006), em estudo sobre as plantas medicinais de uma comunidade rural de Alagoinhas, Pernambuco, já havia mencionado que a importância do hábito está relacionada às características da vegetação local. Para a região amazônica é comum a ocorrência de espécies arbóreas para uso medicinal, como exemplo, no estudo de Shanley \& Luz (2003), foi verificado que seis das doze plantas medicinais mais comercializadas em Belém do Pará eram espécies amazônicas arbóreas.

Os recursos vegetais mais encontrados foram, em ordem de importância, casca $(68,6 \%)$, semente $(9,8 \%)$, exsudato $(7,8 \%)$, caule $(5,9 \%)$, fruto $(5,9 \%)$ e folha $(2,0 \%)$. Os exsudatos correspondem à resina, seiva, látex e óleo-resina. Em algumas espécies aproveita-se mais de um recurso, como são os casos de sucuúba (Himatanthus sucuuba (Spruce ex Müll. Arg.) Woodson) (casca e látex); copaíba (casca e óleoresina); andiroba (as sementes utilizadas para a extração do óleo e a casca) e jatobá (casca e resina).

Nas pesquisas de Almeida \& Albuquerque (2002), na Feira de Caruaru - PE, e de Albuquerque et al. (2007), no Mercado de São José, em Recife - PE, a casca também recebeu maior úmero de citações. Para Albuquerque et al. (2007), as partes mais usadas podem variar de acordo com a região, conforme é percebido ao se observar estudos realizados em outros mercados, como os trabalhos de CostaNeto \& Oliveira (2000), Parente \& Rosa (2001) e Moreira et al. (2002), aonde as folhas são o destaque. Essa variação de acordo a prática cultural regional é importante, mas, além das substâncias ativas apresentarem diferenças nas concentrações de um órgão para o outros, ressalta-se que a disponibilidade do recurso, a facilidade de coleta também são fatores influentes (Coelho-Ferreira 2009).

A facilidade de coleta pode ser exemplificada quanto ao uso de preciosa (Aniba canelilla (Kunth) Mez.), a qual apresenta princípio ativo tanto nas folhas como na casca (Silva et al. 2009), mas, curiosamente apenas a casca é explorada, que é justamente a parte mais acessível na floresta. Frutos e sementes caídos no solo, cascas, látex e resinas são produtos que estão ao alcance dos coletores, o que possivelmente explica a baixa ocorrência de utilização de folhas de espécies arbóreas nativas para comercialização. É interessante ressaltar que as partes das plantas oriundas do extrativismo nesta região são predominantemente de 
Tabela 2. Etnoespécies comercializadas por 20 vendedores de plantas medicinais no DFS/BR-163, Pará, Brasil. (At = Altamira; Av = Aveiro; It = Itaituba; Ja = Jacareacanga; $\mathrm{Ru}=$ Rurópolis; $\mathrm{St}=$ Santarém).

\begin{tabular}{|c|c|c|c|c|c|c|}
\hline Etnoespécie & Nome científico & Família & Hábito & Parte usada & $\begin{array}{l}\mathrm{N}^{\circ} \mathrm{de} \\
\text { citações }\end{array}$ & Municípios \\
\hline Acapú & Vouacapoua americana Aubl. & Fabaceae & Arbóreo & Casca & 1 & At \\
\hline Açoita-cavalo & Luehea divaricata Mart. & Malvaceae & Arbóreo & Casca & 1 & St \\
\hline Amapá & Brosimum parinarioides Ducke & Moraceae & Arbóreo & Casca & 1 & St \\
\hline Andiroba & Carapa guianensis Aubl. & Meliaceae & Arbóreo & $\begin{array}{l}\text { Semente e } \\
\text { casca }\end{array}$ & 13 & At, Av, It, Ru, St \\
\hline Angico & Anadenanthera colubrina (Vell.) Brenan. & Anacardiaceae & Arbóreo & Casca & 4 & It, St \\
\hline Aroeira & Myracrodruon urundeuva Allemão & Anacardiaceae & Arbóreo & Casca & 6 & At, It, St \\
\hline Assacu & Hura crepitans $\mathrm{L}$. & Euphorbiaceae & Arbóreo & Casca & 4 & It, St \\
\hline Babaçu & Attalea speciosa Mart. ex Spreng. & Arecaceae & Arbóreo & Fruto & 5 & It, St \\
\hline Barbatimão & Stryphnodendron sp. & Fabaceae & Arbóreo & Casca & 8 & At, Av, It, St \\
\hline Cajuaçu & Anacardium giganteum W. Hancock ex Engl. & Anacardiaceae & Arbóreo & Casca & 3 & St \\
\hline Cajuí & Anacardium spruceanum Benth. ex Engl. & Anacardiaceae & Arbóreo & Casca & 1 & At \\
\hline Carapanaúba & Aspidosperma nitidum Benth. ex Müll. Arg. & Apocynaceae & Arbóreo & Casca & 4 & $\mathrm{At}, \mathrm{St}$ \\
\hline Castanha-do- Pará & Bertholletia excelsa Bonpl. & Lecythidaceae & Arbóreo & Casca & 2 & At \\
\hline Catuaba & Anemopaegma sp. & Bignoniaceae & Lianescente & Exsudato & 5 & At, It, St \\
\hline Cedro & Cedrela odorata $\mathrm{L}$. & Meliaceae & Arbóreo & Casca & 1 & St \\
\hline Cipó-alho & Adenocalymna sp. & Bignoniaceae & Arbustivo & Caule & 3 & At, St \\
\hline Copaíba & Copaifera spp. & Fabaceae & Arbóreo & $\begin{array}{l}\text { Exsudato e } \\
\text { casca }\end{array}$ & 11 & $\begin{array}{l}\text { At, Av, It, Ja, } \\
\text { Ru, St }\end{array}$ \\
\hline Cumaru & Dipteryx odorata (Aubl.) Willd & Fabaceae & Arbóreo & Semente & 13 & At, Av, It, Ru, St \\
\hline Escada-de-jabuti & Bauhinia guianensis Aubl. & Fabaceae & Lianescente & Caule & 3 & At, St \\
\hline Genipapo & Genipa americana $\mathrm{L}$. & Rubiaceae & Arbóreo & Fruto & 1 & St \\
\hline Imbiriba & Xylopia sp. & Annonaceae & Arbóreo & Semente & 2 & It \\
\hline Imburana & Amburana cearensis (Fr. All.) A.C. & Fabaceae & Arbóreo & Semente & 2 & It \\
\hline Ipê-roxo & Tabebuia impetiginosa (Mart. ex DC.) Standl. & Bignoniaceae & Arbóreo & Casca & 6 & At, Av, It, St \\
\hline Jacareúba & Calophyllum sp. & Clusiaceae & Arbóreo & Casca & 1 & St \\
\hline Jatobá & Hymenaea sp. & Fabaceae & Arbóreo & $\begin{array}{l}\text { Exsudato e } \\
\text { casca }\end{array}$ & 7 & At, Av, It, St \\
\hline Marapuama & Ptychopetalum sp. & Olacaceae & Arbóreo & Casca & 4 & St \\
\hline Muruci & Byrsonima crassifolia (L.) Kunth & Malpighiaceae & Arbóreo & Casca & 1 & St \\
\hline Mururé & Brosimum sp. & Moraceae & Arbóreo & Casca & 2 & At, It \\
\hline Muúba & Bellucia grossularioides (L.) Triana & Melastomataceae & Arbóreo & Casca & 1 & St \\
\hline Pata-de-vaca & Bauhinia forficata Link & Fabaceae & Arbóreo & Folha & 1 & St \\
\hline Pau d'arco & Tabebuia serratifolia (Vahl) G. Nicholson & Bignoniaceae & Arbóreo & Casca & 3 & At, St \\
\hline Pau-para-tudo & Drimys brasiliensis Miers & Winteraceae & Arbóreo & Casca & 1 & St \\
\hline Pau-rosa & Aniba duckei Kosterm. & Lauraceae & Arbóreo & Casca & 1 & St \\
\hline Pedra-ume-caá & Myrcia speciosa (Amshoff) McVaugh & Myrtaceae & Arbustivo & Casca & 1 & St \\
\hline Piquiá & Caryocar villosum (Aubl.) Pers. & Caryocaraceae & Arbóreo & Fruto & 5 & At, Av, It, St \\
\hline Preciosa & Aniba canelilla (Kunth) Mez. & Lauraceae & Arbóreo & Casca & 6 & At, It, St \\
\hline Sacaca & Croton cajucara Benth. & Euphorbiaceae & Arbóreo & Casca & 7 & It, St \\
\hline Sapucaia & Lecythis pisonis Cambess. & Lecythidaceae & Arbóreo & Casca & 2 & At, St \\
\hline Saratudo & Byrsonima sp. & Malpighiaceae & Arbóreo & Casca & 7 & At, It, St \\
\hline Sucupira & Pterodon sp. & Fabaceae & Arbóreo & Semente & 6 & At, It \\
\hline Sucuúba & $\begin{array}{c}\text { Himatanthus sucuuba (Spruce ex Müll. Arg.) } \\
\text { Woodson }\end{array}$ & Apocynaceae & Arbóreo & $\begin{array}{l}\text { Exsudato e } \\
\text { casca }\end{array}$ & 6 & At, It, St \\
\hline Tachi & Tachigali cavipes (Spruce ex Benth.) J.F. Macbr. & Fabaceae & Arbóreo & Casca & 1 & St \\
\hline Unha-de-gato & Uncaria sp. & Rubiaceae & Lianescente & Casca & 8 & At, Av, It, St \\
\hline Uxi & Endopleura uchi (Huber) Cuatrec. & Humiriaceae & Arbóreo & Casca & 7 & At, Av, It, St \\
\hline Verônica & Dalbergia sp. & Fabaceae & Arbustivo & $\begin{array}{l}\text { Caule e } \\
\text { casca }\end{array}$ & 11 & At, Av, It, St \\
\hline Virataia & Annona sp. & Annonaceae & Arbóreo & Casca & 6 & At, It, St \\
\hline 46 & & 21 & & & 195 & \\
\hline
\end{tabular}


árvores que chegam a atingir mais de $30 \mathrm{~m}$ de altura. Outra característica é a baixa ocorrência de plantas frescas, o que pode estar associada ao fato das partes secas das plantas serem mais facilmente conservadas e armazenadas por grandes períodos nas bancas.

A utilização de recursos vegetais que afetam a sobrevivência da planta, como é o caso das cascas, pode prejudicar a conservação das espécies exploradas. Uma alternativa que vem sendo apontada é a substituição por outras partes da planta cujo uso ofereça menor risco, como as folhas. No entanto, deve-se considerar que isso envolve comprovações científicas que necessitam de investimentos em pesquisas para cada espécie, sendo ainda possível uma resistência cultural a mudanças na forma do seu uso medicinal (Zschocke 2000).

Ressalta-se que dentre as plantas catalogadas no presente trabalho, acapu (Vouacapoua americana Aubl.), castanhado-pará (Bertholletia excelsa Bonpl), cedro (Cedrela odorata L.), ipê-roxo (Tabebuia impetiginosa (Mart. ex DC.) Standl.) e pau-rosa (Aniba duckei Kosterm.) estão incluídas na lista de espécies ameaçadas da IUCN (1993). Com relação a dados oficiais brasileiros sobre a conservação biológica, acapú e pau-rosa são classificados como espécies em perigo de extinção e castanha-do-pará como espécie vulnerável (Ibama 1992). Almeida \& Albuquerque (2002), também testemunharam a presença de algumas espécies comercializadas na Feira de Caruaru - PE classificadas como ameaçadas de extinção, sendo este o caso de imburana (Amburana cearensis (Fr. All.) A.C.), angico (Anadenanthera colubrina (Vell.) Brenan.) e aroeira (Myracrodruon urundeuva Allemão), as quais vêm sendo importadas do nordeste para a comercialização nas feiras e mercados de região do DFS/BR-163.

Além do uso medicinal, algumas das plantas catalogadas também são exploradas para o aproveitamento madeireiro, entre elas andiroba, copaíba, cumarú, piquiá (Caryocar villosum (Aubl.) Pers.) e preciosa, cujo uso múltiplo já foi discutido por Shanley \& Luz (2003). Esses autores ressaltaram que o uso madeireiro dessas espécies resulta numa diminuição da disponibilidade de cascas e óleos, o que prejudica sua obtenção para aplicações medicinais.

As espécies pedra-ume-caá (Myrcia speciosa (Amshoff) McVaugh), unha-de-gato (Uncaria sp.), jatobá (Hymenaea sp.), verônica, copaíba, andiroba, jacareúba (Calophyllum sp.) e mururé (Brosimum sp.), comercializadas nos municípios estudados, estão incluídas na lista de espécies prioritárias do projeto Plantas do Futuro da Região Norte (MPEG 2009). Este projeto teve como objetivo identificar plantas nativas da região Norte, com perspectiva do fomentar seu uso pelo pequeno agricultor e por comunidades rurais, além de ampliar a sua utilização comercial, priorizando-a e disponibilizando informações, com vistas a incentivar sua utilização direta, bem como a criação de novas oportunidades de investimento.

O reconhecimento da importância dessas espécies tradicionalmente utilizadas na medicina popular é essencial para maiores avanços no uso racional de produtos florestais de uso medicinal, principalmente nos casos onde a exploração dos recursos confira risco à sobrevivência das espécies.

\section{Curva de Rarefação}

A riqueza observada ( $\mathrm{n}=46$ etnoespécies) é inferior à riqueza calculada a partir do estimador Bootstrap $(\mathrm{n}=50)$ (Fig. 3). Assim, a curva de rarefação evidencia que o esforço de coleta para entrevistas não foi suficiente para a estabilização, mostrando que há a possibilidade de outras etnoespécies medicinais oriundas do extrativismo serem comercializadas nesses locais. Contudo, isso poderia ser observado com o aumento do número de entrevistados.

É importante lembrar que a curva de rarefação demonstra o quanto o esforço de coleta se aproximou da real riqueza de etnoespécies. Quando se alcança estabilização, não quer dizer que naquela amostra se esgotaram as possibilidades de novas inclusões de etnoespécies medicinais, mas que a inclusão de novos itens tende a ser cada vez menor, uma vez que espécies raras costumam ser adicionadas após muitas amostragens. Com relação ao presente estudo, ressalta-se que é possível que algumas plantas, ausentes nos pontos de venda no momento da entrevista, não tenham sido lembradas pelos mesmos, não sendo assim incluídas. Mesmo assim, considera-se que houve uma boa aproximação entre a amostra e as estimativas de riqueza.

\section{Similaridade de etnoespécies entre os mercados}

O maior número de etnoespécies ocorreu em Santarém (40), Altamira (26) e Itaituba (23). Aveiro e Rurópolis apresentaram oito e três ocorrências, respectivamente, enquanto que Jacareacanga foi o município de menor expressão, observando-se apenas a comercialização do óleo-resina de copaíba. Os resultados para o índice de Sørensen mostram que a maior similaridade ocorreu entre Altamira e Santarém $(0,67)$, Altamira e Itaituba $(0,65)$ (Tab. 3).

A partir da análise de similaridade, observou-se o agrupamento em dois eixos para os diferentes municípios. Altamira, Itaituba, Santarém e Aveiro formam um grupo que apresenta maior número de etnoespécies entre os vendedores de plantas medicinais; em oposição, Rurópolis e Jacareacanga formam outro agrupamento caracterizado por um baixo número de etnoespécies (Fig. 4).

Dentro do grupo mais diversificado, Santarém, Itaituba e Altamira compartilham seis etnoespécies exclusivas, aroeira, catuaba (Anemopaegma sp.), preciosa, saratudo (Byrsonima sp.), sucuúba (Himatanthus sucuuba (Spruce ex Müll. Arg.) Woodson) e virataia (Annona sp.). Para esses municípios a alta similaridade também se deve à presença das plantas de origem nordestinas aroeira, barbatimão, angico e sucupira, que são registradas apenas entre os informantes destes locais. Santarém destaca-se como centro diversificado de produtos medicinais e apresenta o maior número de 


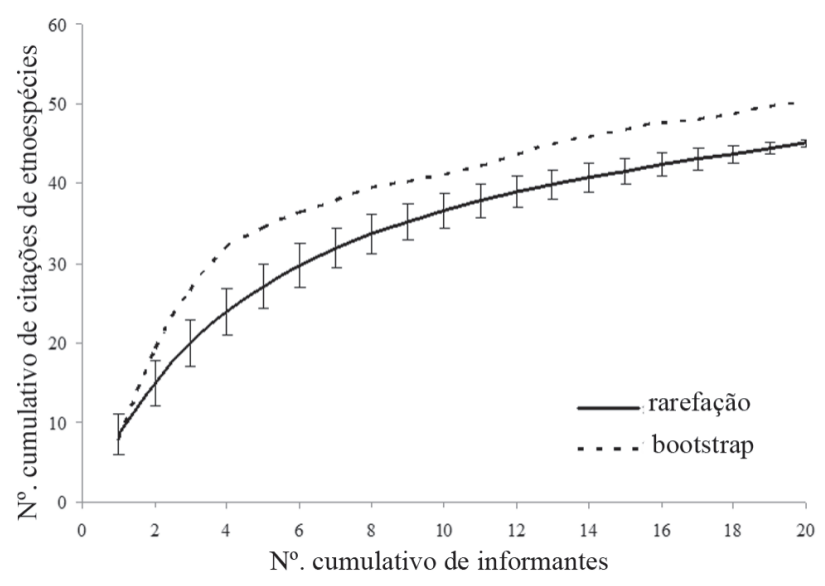

Figura 3. Curva de rarefação para as plantas comercializadas por vendedores de plantas medicinais no DFS/BR-163, Pará, Brasil. n=20 informantes.

ocorrências exclusivas (14). Parte da sua similaridade com Itaituba é explicada pelo fato de ser pólo fornecedor destas mercadorias, conforme afirmam alguns feirantes.

De uma maneira geral, as plantas medicinais encontradas são tradicionalmente utilizadas pela população amazônica e já foram registradas em outros estudos sobre mercados. Espécies como andiroba, copaíba e cumarú, comuns à maioria dos locais estudados, são frequentes em mercados de plantas medicinais na Amazônia (Berg 1984; Coelho-Ferreira 1996; Pinto \& Maduro 2003; Shanley \& Luz 2003; Andel et al. 2007). O fato de uma planta estar presente em determinado mercado pode ser resultado da demanda local pelo produto, sendo que nos centros mais populosos como Altamira, Santarém e Itaituba essa procura seria mais intensa e diversificada. Segundo Bye \& Linares (1983), a presença de determinadas espécies em um mercado, durante longos períodos de tempo, sugere que estas produzem efeitos que são esperados pelos consumidores, sendo continuamente testadas, avaliadas, e procuradas por causa de suas reconhecidas propriedades e eficácia.

Levando-se em conta que os mercados funcionam como centros provedores de produtos naturais à população urbana, como plantas medicinais, a procura por determinados itens induz à presença de novos produtos nos estoques dos vendedores, e na medida em que são reutilizados, podem passar a fazer parte do repertório local de produtos medici-

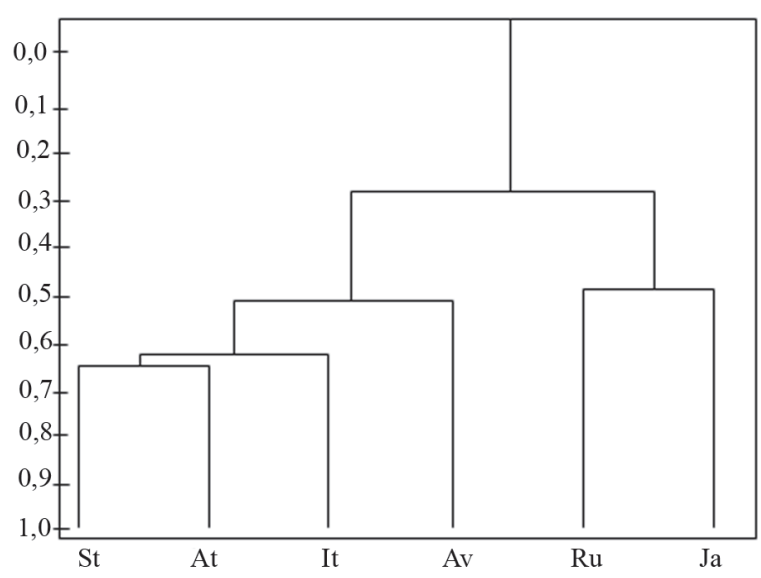

Figura 4. Dendograma de similaridade de Sørensen das etnoespécies medicinais comercializadas nos municípios do DFS/BR-163, Pará, Brasil. (At = Altamira; $\mathrm{Av}=$ Aveiro; It = Itaituba; Ja = Jacareacanga; $\mathrm{Ru}=$ Rurópolis; $\mathrm{St}=$ Santarém $)$.

nais, o que contribui para a sua popularidade e divulgação entre os centros comerciais mais movimentados. Isto se intensificaria para os municípios em questão por participarem de rotas comerciais importantes na região.

\section{Disponibilidade dos produtos $x$ sazonalidade}

A sazonalidade corresponde a um dos fatores que influenciam o abastecimento de produtos de plantas medicinais nos estabelecimentos estudados. Como era de se esperar, verificou-se que a relação do número de plantas medicinais disponíveis para o abastecimento dos estoques dos feirantes variou entre o inverno e o verão. Para aqueles disponíveis apenas em determinadas épocas do ano, a estocagem tem sido estratégia importante para garantir a comercialização em períodos de escassez.

É no período seco que chega para os vendedores a maioria dos produtos medicinais, entre eles as cascas, principalmente de espécies como ipê-roxo, sacaca (Croton cajucara Benth.), uxi (Endopleura uchi (Huber) Cuatrec.), verônica e unha-de-gato. Quanto aos exsudatos, citam-se o látex de sucuúba e assacú, assim como a resina de jatobá e o óleo-resina de copaíba, os quais são bastante procurados nos mercados. A estocagem desses produtos é importante para o consumo no inverno, quando, segundo os vendedores, aumentam a procura por remédios naturais em suas

Tabela 3. Matriz de similaridade de Sørensen para etnoespécies medicinais comercializadas nos municípios de Altamira, Aveiro, Itaituba, Jacareacanga, Rurópolis e Santarém.

\begin{tabular}{lllll}
\hline & Altamira & Itaituba & Santarém & Aveiro \\
\hline Altamira & & & & \\
Itaituba & 0,6511628 & & & \\
Santarém & 0,6666667 & 0,566038 & & \\
Aveiro & 0,4285714 & 0,518519 & 0,250000 & 0,000000 \\
Jacareacanga & 0,0740741 & 0,083333 & 0,048780 & 0,307692 \\
Rurópolis & 0,2068970 & 0,230769 & 0,315789 & 0,500000 \\
\hline
\end{tabular}


bancas, principalmente aqueles relacionados a problemas respiratórios.

Dentre os produtos que tem seu abastecimento reduzido durante o inverno, as cascas são as mais afetadas. Alguns informantes explicaram que nesta época é mais difícil caminhar pela mata e realizar a coleta. Entretanto, é no período chuvoso que são fornecidos os óleos de piquiá, obtido da polpa dos frutos, e os óleos de cumarú e andiroba, extraídos das sementes, pelo fato destas espécies frutificam nesta época. Desta forma, há uma complementaridade de produtos medicinais diferentes ao longo do ano para o abastecimento dos mercados locais. Obviamente, os óleos são os produtos com preços mais elevados.

\section{Conservação e armazenamento dos produtos}

As cascas são vendidas para os feirantes já desidratadas, e são armazenadas na própria banca, em sacas de fibra, caixas de papelão, sacolas e baldes plásticos. Algumas vezes o processo de desidratação é finalizado na própria banca de venda. De tempos em tempos, as cascas precisam ser novamente expostas ao sol, de acordo com os informantes, para combater a contaminação por microorganismos.

Os óleos e látex são acondicionados em garrafas de vidro de $1 \mathrm{~L}$ e garrafas PET de 2L. Segundo os informantes, a proteção contra a luz solar, umidade e poeira são os principais cuidados para a conservação destes produtos. Isso vai de encontro às recomendações feitas por Mendonça \& Ferraz (2007), que aconselham o acondicionamento de óleos vegetais em recipientes de vidro âmbar, o qual conserva melhor as propriedades físicas e químicas do produto.

Quanto à comercialização, foram identificados quatro tipos de embalagem: sacos plásticos, garrafas PET, garrafas de vidro de $1 \mathrm{~L}$ e frascos de vidro pequenos $(20 \mathrm{~mL})$ reutilizados, adquiridos em hospitais. De uma maneira geral todas são compradas de fornecedores locais ou recicladas.

Uma das principais medidas contra umidade, insetos e roedores é o uso de lonas estendidas sobre as bancas ao final do dia de trabalho. As formas de armazenamento e embalagem de plantas medicinais por vendedores são recorrentes, tendo sido também observadas por Araújo et al.(2009). Esse tipo de armazenamento é considerado por alguns autores (Máthé \& Franz 1999; Araújo et al. 2009) como apropriado para esses estabelecimentos, ajudando a proteger os produtos contra as variações de temperatura, umidade e do contato com impurezas.

\section{Cadeia produtiva das plantas medicinais}

A visualização da cadeia de comercialização para a área pode ser observada na Fig. 5. Os principais fornecedores de plantas medicinais são produtores rurais - tanto de comunidades ribeirinhas como de agrovilas ou assentamentos rurais - e indígenas, os quais têm como principais vias de escoamento da produção o rio Tapajós e as rodovias Transamazônica (BR-230) e Cuiabá-Santarém (BR-163).
Foi raramente constatado a comercialização direta entre produtor e consumidor final, o que demonstra a importância dos feirantes locais como elos centrais da cadeia produtiva. Essa característica é comum entre os mercados visitados nos diferentes municípios do DFS/BR-163.

Os feirantes parecem não conhecer com exatidão as comunidades provedoras de seus produtos. Referem-se de maneira genérica aos fornecedores de plantas medicinais: "essas cascas, quem trazem são os colonos e os ribeirinhos...". Provavelmente, isso se deva ao fato das relações sociais entre esses atores serem, na maioria das vezes, restritas ao processo de comercialização.

Foi constatada a importância do mercado de Santarém para o fornecimento de produtos medicinais aos feirantes de Itaituba, através da atuação de atravessadores. O principal local de obtenção dos produtos em Santarém é o Mercadão 2000 , onde são comprados principalmente o óleo de andiroba, copaíba e cascas. Outros atravessadores atuam na importação de plantas medicinais do Nordeste Brasileiro. A conexão com esta região, principalmente com os Estados do Piauí e Maranhão, está relacionada à manutenção de vínculos entre os imigrantes e sua terra de origem. Diversas plantas medicinais da flora daquela região são procuradas nos mercados locais do DFS/BR-163, principalmente em Altamira, Itaituba e Santarém.

Essa constatação corrobora a afirmação de Albuquerque et al. (2007) sobre a importância dos mercados tradicionais como sistema de reunião, manutenção e difusão do conhecimento empírico de diferentes regiões. Estes autores sugerem uma linha de interpretação dos mercados como sistemas abertos e dinâmicos, que tendem a conservar o seu repertório de espécies, ao mesmo tempo em que absorvem novas espécies.

A influência da cultura nordestina no estabelecimento de canais de comercialização para a importação de plantas medicinais também foi constatada no estudo de Pinto \& Maduro (2005), os quais também destacaram que o processo de ocupação de Boa Vista em Roraima afetou a diversificação da farmacopéia regional, inclusive registrando a ocorrência de espécies comuns com o presente estudo, como angico, aroeira, imburana e imbiriba.

As principais características dessa cadeia produtiva são: a predominância do setor informal e o mercado com abrangência principalmente local e regional. Os consumidores no âmbito local são geralmente donas de casa e rezadeiras. Quanto à demanda externa, foi relatado pelos feirantes o consumo por pessoas de municípios vizinhos e de outros estados. Segundo estes, os compradores de outros estados são frequentemente turistas que aproveitam para comprar produtos naturais encontrados nas feiras. Esse último tipo de consumidor é mencionado nos municípios de Altamira, Itaituba e Santarém.

Cadeias de abrangência local têm como característica a eliminação de inúmeras fases da produção até a comercialização, em razão da baixa utilização de tecnologias para a 


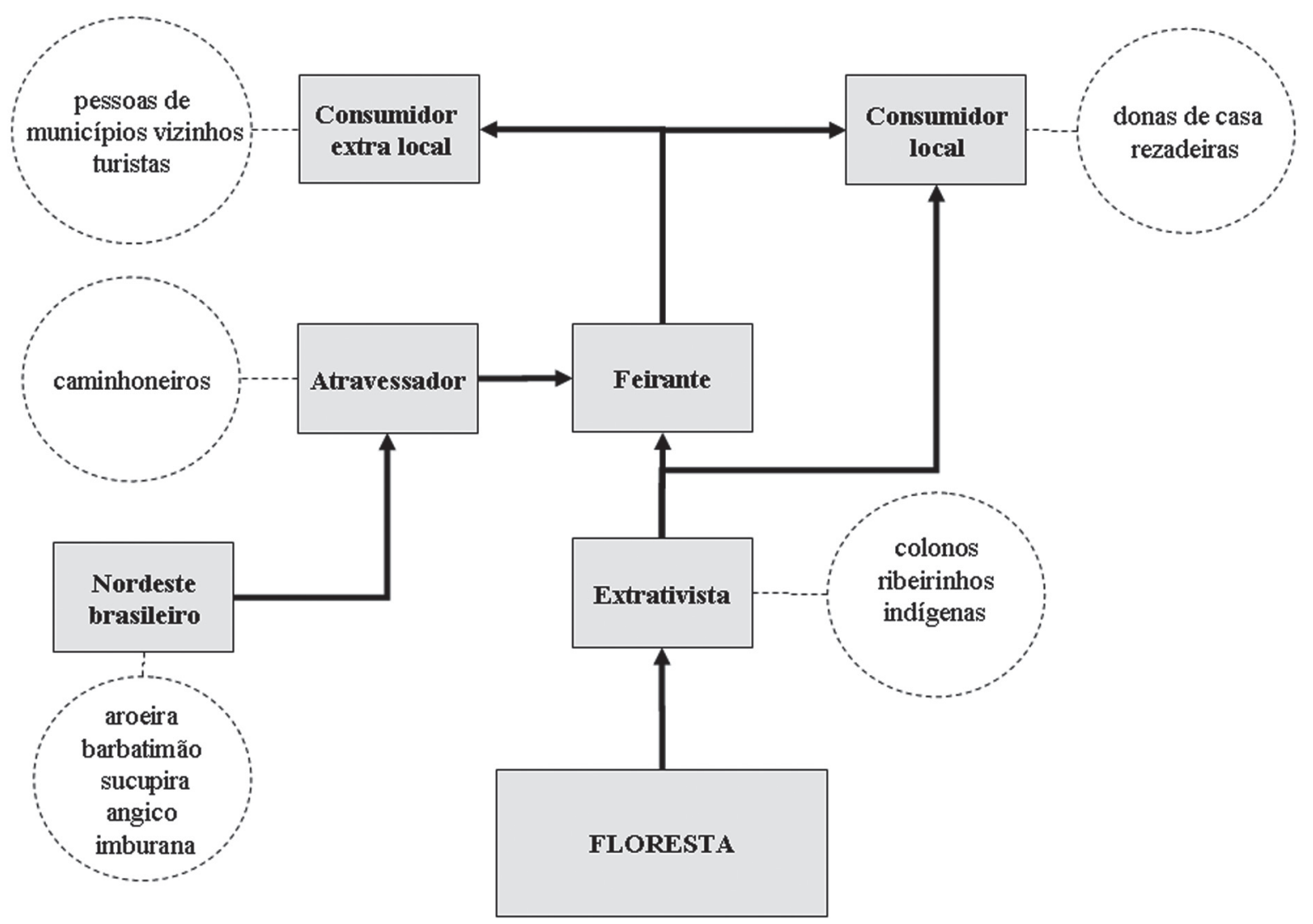

Figura 5. Cadeia produtiva das plantas medicinais no DFS/BR-163, Pará, Brasil.

transformação dos produtos (Nair et al. 2007). Quando isso ocorre fica restrito a poucos agentes, no caso em questão, uma forma de transformação é a preparação de garrafadas com a mistura de várias plantas aplicadas para diversos fins como gripes, resfriados, impotência, etc.

O comércio tradicional muitas vezes proporciona baixos rendimentos, situação específica do setor informal, o qual tem como característica unidades de produção de pequeno porte, à margem de segmentos modernizados da economia, onde a meta não é a acumulação de capital, mas a sobrevivência das pessoas diretamente envolvidas (Dedecca 2007).

\section{Conclusões}

Apesar de o número de etnoespécies observado ser expressivo, a realização de mais entrevistas seria importante para se atingir a suficiência amostral, que, de acordo com o índice Bootstrap, seria de pelo menos quatro ocorrências a mais.

Existe variação na riqueza de plantas medicinais entre os municípios estudados. Ao mesmo tempo, ocorre uma alta similaridade de etnoespécies mencionadas pelos vendedores dos municípios de Altamira, Santarém e Itaituba, cujo resultado é influenciado pela presença de plantas oriundas do nordeste brasileiro.

O fato das cascas, obtidas principalmente de espécies arbóreas, serem as partes vegetativas mais comumente encontradas nas bancas dos vendedores, remete a preocupações sobre a conservação das espécies exploradas, principalmente para aquelas classificadas como ameaçadas de extinção, como acapú (Vouacapoua americana Aubl.), castanha-dopará (Bertholletia excelsa Bonpl.), cedro (Cedrela odorata L.), ipê-roxo (Tabebuia impetiginosa (Mart. ex DC.) Standl.) e pau-rosa (Aniba rosaeodora Ducke).

Há de se ressaltar que esse comércio constitui uma das opções de atividades para trabalhadores no setor informal, num contexto justificado pela sobrevi vência, devido às dificuldades de obtenção de renda, sendo que alguns atores dependem de recursos extras, como benefícios de programas sociais do governo federal.

\section{Agradecimentos}

Ao CNPq, pela concessão de bolsa de Mestrado ao primeiro autor; ao Projeto Integrado MCT/Embrapa - PIME, pelo financiamento de todas as viagens para levantamento das informações; aos feirantes pela valiosa atenção, essen- 
cial para a pesquisa; ao Museu Paraense Emílio Goeldi e à Universidade Federal Rural da Amazônia, pelo apoio durante a construção do trabalho no âmbito do Programa de Pós-Graduação em Biologia com concentração em Botânica Tropical.

\section{Referências bibliográficas}

Albuquerque, U.P. 2006. Re-examining hypotheses concerning the use and knowledge of medicinal plants: a study in the caatinga vegetation of NE Brazil. Journal of Ethnobiology and Ethnomedicine 2: 1-10.

Albuquerque, U.P.; Lucena, R.F.P. \& Cunha, L.V.F.C (Orgs.). 2008. Métodos e técnicas na pesquisa etnobotânica. 2. ed. Recife, Comunigraf.

Albuquerque, U.P.; Monteiro, J.M.; Ramosa, M.A. \& Amorim, E.L.C. 2007. Medicinal and magic plants from a public market in northeastern Brazil. Journal of Ethnopharmacology 110: 76-91.

Alcorn, J.B. 1995. The scope and aims of ethnobotany in a development world. Pp. 23-39. In: Schultes, R.E. \& Reis, S.V. Ethnobotany: evolution of a discipline. Portland, Dioscorides Press.

Almeida, C.F.C.B.R. \& Albuquerque, U.P. 2002. Uso e conservação de plantas e animais medicinais no estado de Pernambuco (Nordeste do Brasil): um estudo de caso. Interciencia 27(6): 276-285.

Almeida, S.S.; Amaral, D.D.; Silva, A.S.L.; Rosário, C.S. \& Pereira, J.L.G. 2008. Avaliação do estado de conhecimento da flora na região da BR 163 no Estado do Pará. Pp. 85-110. In: Venturieri, A. (Org.). Zoneamento ecológico-econômico da área de influência da rodovia BR 163 (Cuiabá-Santarém). Vol. 2. Belém, Embrapa Amazônia Oriental.

Andel, T.; Behari-Ramdas, J.; Havinga, R. \& Groenendijk, S. 2007. The medicinal plant trade in Suriname. Ethnobotany Research \& Applications 5: 351-372.

APG (The Angiosperm Phylogeny Group) III. 2009. An update of the Angiosperm Phylogeny Group classification for the orders and families of flowering plants: APG III. Botanical Journal of the Linnean Society 161: 105-121.

Araújo, A.C.; Silva, J.P.; Cunha, J.L.X.L. \& Araújo, J.L.O. 2009. Caracterização socio-econômico-cultural de raizeiros e procedimentos pós-colheita de plantas medicinais comercializadas em Maceió, AL. Revista Brasileira Plantas Medicinais 11(1): 81-91.

Araújo, E.L. \& Ferraz, E.M.N. 2008. Análise da vegetação: amostragem, índices de diversidade e aplicações na etnobotânica. In: Albuquerque, U.P.; Lucena, R.F.P. \& Cunha, L.V.F.C. (Orgs.). Métodos e técnicas na pesquisa etnobotânica. Recife, Comunigraf.

Araújo, R.; Castro, E.; Rocha, G.; SÁ, M. E.; Mathis, A.; Monteiro, M.; Puty, C.; Monteiro, R.; Canto, O. \& Benatti, J. 2008. Estado e sociedade na BR-163: desmatamento, conflitos e processos de ordenamento territorial, Pp. 13-84. In: Castro, E. (Org.). Sociedade, território e conflitos: BR-163 em questão. Belém, NAEA.

Berg, M.E.V.D. 1984. Ver-o-peso: the ethnobotany of an amazonian market Pp.140-145. In: Prance, G.T. Kallunki. Advances in Economic Botany, Vol.1. New York, The New York Botanical Garden.

Brasil, Grupo de Trabalho Interinstitucional do Distrito Florestal Sustentável da BR 163. 2006. Plano de Ação (2006-2007). http://www. mma.gov.br (Acesso em 13/02/2010).

Botha, J.; Witkowski, E.T.F. \& Shackleton, C.M. 2004. Market profiles and trade in medicinal plants in the Lowveld, South Africa. Environmental Conservation 31(1): 38-46.

Bye, R.A. \& Linares, E. 1983.The role of plants found in the mexican markets and their importance in ethnobotanical studies. Journal of Ethnobiology 3: 1-13.

Castro, E.; Monteiro, R. \& Castro, C.P. 2004. Dinâmica de atores, uso da terra e desmatamento na Rodovia Cuiabá-Santarém. Paper 180. Belém, NAEA.

Coelho-Ferreira, M. 1996. Le marché des plantes medicinales à Manaus, Pp.173-175. In: Emperaire, L. (Org.). La forêt in jeux: l'extrativisme en Amazonie Centrale. vol. 1. Paris, ORSTOM/UNESCO.
Coelho-Ferreira, M. 2009. Medicinal, Knowledge and Plant Utilization in an Amazonian costal Community of Marudá, Pará State (Brazil). Journal of Ethnopharmacology 126: 159-175.

Costa-Neto, E.M. \& Oliveira, M.V.M. 2000. The use of the medicinal plants in the country of Tanquinho, State of Bahia, northeastern Brazil. Revista Brasileira de Plantas Medicinais 2: 1-8.

Dedecca, C.S. 2007. Setor informal e informalidade no Brasil. Ciência Hoje 39(234): 18-23.

Godoy, W.I. \& Anjos, F.S. 2002. A importância das feiras livres ecológicas: um espaço de trocas e saberes da economia local. Revista Brasileira de Agroecologia 2(1): 364-368.

Hanazaki N.; Tamashiro J.Y.; Leitão-Filho H.F. \& Begossi A. 2000. Diversity of plant use in two caiçara communities from the atlantic forest coast, Brazil. Biodiversity and Conservation 9: 597-615.

Ibama. 1992. Portaria No 37-N, de 3 de abril de 1992: reconhece a lista oficial de espécies da flora brasileira ameaçada de extinção. Brasília, Ministério do Meio Ambiente. http://www.mma.gov.br (Acesso em 7/05/2010).

IUCN. 1993. Guidelines on the conservation of medicinal plants. Gland, IUCN, WHO e WWF.

Laird, S.A.; Wynberg, R. \& Mclain, R.J. 2009. Wild product governance: laws and policies for sustainable and equitable non-timber forest product use. A United Nations University, Centre for International Forestry Research, People and Plants International, University of Cape Town, and Institute for Culture e Ecology Policy Brief.

Martin, G.J. 1995. Ethnobotany: a people and plants conservation manual. Londres, Chapman \& Hall.

Máthé, A. \& Franz, C. 1999. Good agricultural practices and the quality of phytomedicines. Journal of Herbs, Spices e Medicinal Plants 6: 101-3.

Mati, E.; Boer, H. 2011. Ethnobotany and trade of medicinal plants in the Qaysari Market, Kurdish Autonomous Region, Iraq. Journal of Ethnopharmacology 133: 490-510.

Mayo, J.M. 1991. The american public market. Journal of Architectural Education 45(1): 41-57.

Mendonça, A.P. \& Ferraz, I.D.K. 2007. Óleo de andiroba: processo tradicional da extração, uso e aspectos sociais no estado do Amazonas, Brasil. Acta Amazonica 37(3): 353-364.

Monteiro, J.M.; Araújo, E L.; Amorim, E.L.C. \& Albuquerque, U.P. 2010. Local markets and medicinal plant commerce: a review with emphasis on Brazil. Economic Botany 64(4): 352-366.

Moreira, R.C.T.; Costa, L.C.B.; Costa, R.C.S. \& Rocha, E.A. 2002. Abordagem etnobotânica a cerca do uso de plantas medicinais na Vila Cachoeira, Ilhéus, Bahia, Brasil. Acta Farmacéutica Bonaerense 21: 205-211.

MPEG, Museu Paraense Emílio Goeldi. 2009. Espécies de plantas selecionadas como plantas do futuro da Região Norte - Lista prioritária 1 (Lista Verde). http://www.museu-goeldi.br (Acesso em 06/05/2010).

Nair, C.T.S. 2007. Escala, mercados y economía: las empresas pequeñas en un entorno en vías de mundialización. Unasylva 228(58): 3-10.

Parente, C.E.T. \& Rosa, M.M.T. 2001. Plantas comercializadas como medicinais no Município de Barra do Piraí, RJ. Rodriguésia 52(80): 47-59.

Peroni, N.; Araujo, H.F.P. \& Hanazaki, N. 2008. Métodos ecológicos na investigação etnobotânica e etnobiológica: o uso de medidas de diversidade e estimadores de riqueza. Pp. 199-225. In: Albuquerque, U.P.; Lucena, R.F.P. \& Cunha, L.V.F.C. (Orgs.). Métodos e técnicas na pesquisa etnobotânica. Recife, Comunigraf.

Pinto, A.A.C. DA \& Maduro, C.B. 2003. Produtos e subprodutos da medicina popular comercializados na cidade de Boa Vista, Roraima. Acta Amazônica 33(2): 281-290.

Rozelle, S.; Huang, J. \& Benziger, V. 2003. Continuity and change in China’s rural periodic markets. The China Journal 49: 89-115.

Schittini, G.M.; Franco, J.L.A.; Drummond, J.A. 2008. Áreas protegidas no âmbito do Plano BR-163 sustentável: motivações dos atores envolvidos na criação e implicações sobre a sua gestão futura. In: IV Encontro Nacional da Anppas, Brasília.

Shanley, P. \& Luz, L. 2003. The impacts of forest degradation on medicinal plant use and implications for health care in Eastern Amazonia. BioScience 53(6): 573-584. 
Silva, J.R.A.; Carmo, A.D.F.M.; Reis, É.M.; Machado, G.M.C.; Leon, L.L.; SILVA, B.O.; Fereira, J.L.P. \& Amaral, A.C.F. 2009. Chemical and biological evaluation of essential oils with economic value from Lauraceae species. Journal of Brazilian Chemical Society 20(6): 1071-1076.

Veeman, M. 2002. Conociendo los mercados locales y regionales para produtos forestales, Pp. 81-116. In: Campbell, B.M., Luckert, M.K. (Eds.). Evaluando la cosecha oculta de los bosques. Montevideo, Nordan- Comunidad.

Venturieri, A. (Org.). 2008. Zoneamento ecológico-econômico da área de influência da rodovia BR 163 (Cuiabá-Santarém). Vol. 1. Belém, Embrapa Amazônia Oriental.
Williams, V.L.; Balkwill, K.; Witkowski. E.T.F. 2000. Unraveling the commercial market for medicinal plant parts on the Witwatersrand, South Africa. Economic Botany 54: 310-327.

Williams, V.L.; Witkowski, E.T.F.; Balkwill, K. 2005. Application of diversity indices to appraise plant availability in the traditional medicinal markets of Johannesburg, South Africa. Biodiversity and Conservation 14: 2971-3001.

Zschocke, S.; Rabe, T.; Taylor, J.L.S.; Jäger, A.K. \& Staden, J. van. 2000. Plant part substitution - a way to conserve endangered medicinal plants? Journal of Ethnopharmacology 71: 281-292. 